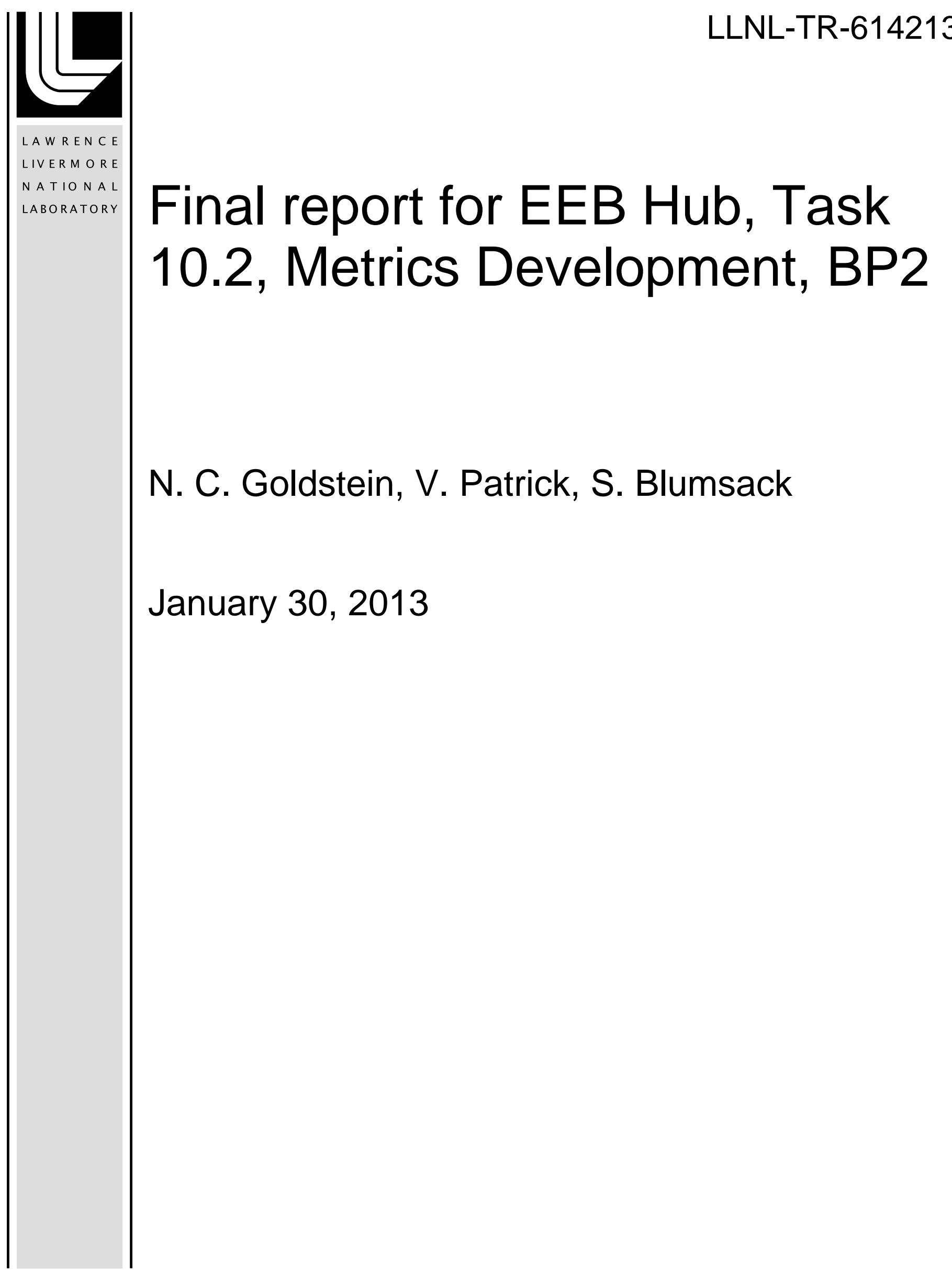


This document was prepared as an account of work sponsored by an agency of the United States government. Neither the United States government nor Lawrence Livermore National Security, LLC, nor any of their employees makes any warranty, expressed or implied, or assumes any legal liability or responsibility for the accuracy, completeness, or usefulness of any information, apparatus, product, or process disclosed, or represents that its use would not infringe privately owned rights. Reference herein to any specific commercial product, process, or service by trade name, trademark, manufacturer, or otherwise does not necessarily constitute or imply its endorsement, recommendation, or favoring by the United States government or Lawrence Livermore National Security, LLC. The views and opinions of authors expressed herein do not necessarily state or reflect those of the United States government or Lawrence Livermore National Security, LLC, and shall not be used for advertising or product endorsement purposes.

This work performed under the auspices of the U.S. Department of Energy by Lawrence Livermore National Laboratory under Contract DE-AC52-07NA27344. 


\section{Final report for EEB Hub, Task 10.2, Metrics Development, BP2}

Noah Goldstein, LLNL

Valerie Patrick, Bayer Material Science

Seth Blumsack, Penn State

$\operatorname{Jan} 28^{\text {th }}, 2013$

The long-term EEB Hub goal quantified during BP2 is to accelerate the adoption of advanced energy retrofits to reduce building energy use $20 \%$ by 2020 for commercial buildings in the greater Philadelphia region. For each budget period, the EEB Hub develops deliverables targeted at methods and means to achieve this long-term goal. The purpose of metrics is to regularly measure progress towards achieving the annual budget-period deliverables.

In July 2012, the EEB Hub organized a workshop, led by Noah Goldstein and Valerie Patrick, to generate a number of metrics that would describe how the Hub would be progressing towards its long-term goals. That workshop led to a set of 27 "goal related" metrics that can be used to measure progress of activities towards the Hub's 2020 goals (see "EEB Hub Metrics Session 24Jul2012 FINAL Report V1.docx" for details about the metrics workshop).

Working with Hub Management and DOE, that list was used to create seven Hub-wide deliverables for BP3, along with specific performance metrics for each Task. The Task-level performance metrics are aligned with relevant Hub-level deliverables as well as the overall Hub goal of $20 \%$ energy reduction in commercial buildings by 2020 . The Task-level performance metrics take the form of quarterly milestones that measure progress towards a defined Task-level deliverable for BP3. The program assessment subtask worked with individual BP3 Task leads to construct preliminary metrics, as seen in appendix A. Those metrics are both numerical and qualitative, and are flexible to account for interim milestones. In BP3, Hub management, the program assessment subtask, and the Task leads will use the developed metrics to track progress towards meeting Task-level deliverables and to ensure continued alignment with overall Hub goals. DOE will also use the metrics to ensure the Hub is on track for the completion of the seven deliverables.

With three exceptions, each of the seven Hub deliverables for BP3 maps to a specific Task. Thus, seven of the ten Tasks effectively have ownership of seeing that a specific Hub-level deliverable is met in BP3. Tasks 1 (Management), Task 3 (Building Energy Informatics), and Task 10 (reporting) do not have explicit Hub-level deliverables, yet metrics were developed for those tasks as well, as a management tool.

In Appendix A, the preliminary metric "tool" is presented. This will be used by Task leads as a starting point to fill in, with their Sub-task participants, to manage the progression of work over the course of BP3. 
APPENDIX A 
Task 1

Deliverable:

$12 / 28 / 12$

1/9/2013 If changed, please insert most recent Task deliverable here: Sound financial and program management principles and practices have been applied to administer/govern the EEB Hub.

Metrics:

01/09/13

1.1 Financial

Monthly percent of on-time invoicing by EEB Hub performers compared to the target

1.2 Communication

1.3 Management

1.3 .1

1.3.2

$\mathrm{RACl}$ matrix completed

$\mathrm{RACl}$ matrix followed and evaluated by Task leads
Date 1

date 
Task 2

Deliverable:

Task Level Deliverable and Metrics

12/28/12 Beta release of a suite of user-friendly simulation tools that will require no more than 24 hours of input time, interface with existing software, and are capable of predicting energy use in the studied types of commercial buildings with accuracy of $+/-5 \%$ at the stage of advanced energy retrofit investment decision making.

\section{NCG: Is the goal $\mathbf{5 \%}$ or $\mathbf{1 5 \%}$ ?? Please clarify}

If changed, please insert most recent Task deliverable here:

Metrics:

$12 / 28 / 12$

2.1 Accuracy Definitions

2.1.1

Definition of $15 \%$ accuracy and progress towards this objective

2.1 .2

At the SUBTASK or MODEL/SIMULATION TOOL level: A definition of accuracy that is measurable

2.1 .3

Establishment of procedures to measure that accuracy

Achievement of XX\% accuracy

2.1.4 Achievement of $15 \%$ accuracy

2.2 Model Development Definition of 24 hour input requirement and progress towards this objective

2.2.1 Design framework per MODEL - to measure or estimate input time

2.2.2 XX hour entry for each model (e.g. 48 hours)

2.2.3 24 hour entry for every model

2.3 Platforms

Definition of contribution to the simulation platform and progress towards this objective

2.3.1

2.3.2

2.3.3

2.3.4

Number of number of building/rooms/systems models rendered of relevant demonstration project buildings

Approximate number of simulations runs, of relevant demonstration project buildings

Number of stakeholder companies (or owner groups), not in Hub, who are using tools. Through letters, emails, downloads etc.... For each Model

Date

Mode

?

?

?

Mode

?

?

Mode

?

mont

mont

mont 
Task 3

Task Level Deliverable and Metrics

Deliverable: $\quad 12 / 28 / 12$

Demonstrated building energy information storage, retrieval and display prototypes to enable internal and external stakeholders to make more informed decisions related to Advanced Energy Retrofit projects and policies.

If changed, please insert most recent Task deliverable here:

Metrics: $\quad 12 / 28 / 12$

3.1 Matrix Update Percent complete for each square in matrix

\begin{tabular}{|c|c|c|c|c|c|c|c|c|c|}
\hline $\begin{array}{c}\text { Stages of Development } \\
\text { Database Types }\end{array}$ & Number of Use Cases & $\begin{array}{l}\text { Use Cases } \\
\text { Defined }\end{array}$ & $\begin{array}{l}\text { Requirements } \\
\text { Documented }\end{array}$ & $\begin{array}{l}\text { Prototype } \\
\text { Developed }\end{array}$ & $\begin{array}{l}\text { Prototype } \\
\text { Validated }\end{array}$ & $\begin{array}{l}\text { Production System } \\
\text { Developed }\end{array}$ & $\begin{array}{c}\text { Production System } \\
\text { Validated }\end{array}$ & $\begin{array}{c}\text { Production System } \\
\text { Deployed }\end{array}$ & $\begin{array}{c}\text { Production System } \\
\text { Adopted }\end{array}$ \\
\hline Information Standards & 2 by $Q 2$ & 2 by $Q 2$ & 2 by $Q 2$ & 2 by Q3 & Q3 & 2 by $Q 3$ & 2 by $Q 4$ & 2 by $Q 4$ & 2 by $Q 4$ \\
\hline BIM & 2 by $Q 2$ & 2 by $Q 2$ & 2 by $Q 2$ & 2 by $Q 3$ & 2 by Q3 & 2 by $Q 3$ & 2 by $Q 4$ & 2 by $Q 4$ & 2 by $Q 4$ \\
\hline $\begin{array}{l}\text { Building Performance } \\
\text { Database }\end{array}$ & 2 by Q2 & 2 by Q2 & 2 by Q2 & 2 by Q3 & 2 by Q3 & 2 by Q3 & 2 by Q4 & 2 by Q4 & 2 by $Q 4$ \\
\hline $\begin{array}{c}\text { Regional Building Energy } \\
\text { Database }\end{array}$ & 2 by Q2 & 2 by Q2 & 2 by Q2 & 2 by Q3 & 2 by Q3 & 2 by Q3 & 2 by $Q 4$ & 2 by $Q 4$ & 2 by $Q 4$ \\
\hline Energy Dashboards & 2 by $Q 2$ & 2 by $Q 2$ & 2 by $Q 2$ & 2 by Q3 & 2 by Q3 & 2 by Q3 & 2 by $Q 4$ & 2 by $Q 4$ & 2 by $Q 4$ \\
\hline
\end{tabular}


Task 4

Deliverable:

$12 / 28 / 12$

Tevel Deliverable and Metrics

A prototype building operations platform that overlays on existing building control systems to enable cost effective (minimum 15\% average annual return over 10 years) deployment of advanced sensor, control, diagnostic and decision-making technologies that have the potential

to achieve up to 30 percent annual energy savings in applicable commercial buildings.

If changed, please insert most recent Task deliverable here:

Metrics:

$12 / 28 / 12$

4.1 Platform Completion

Percent completion of operations platform implementation, demonstration, and assessments for three buildings - (calculated using percent completion of key actions weighted according to effort)

4.2 Energy Performance

HVAC energy savings relative to energy savings targets established for each of the three buildings
B101

$25 \%$ complete by Q2

15\% by Q2 Sample dates
B661 by Q2

15\% by Q2
Buildi

$25 \%$ com

by $Q$

$15 \%$ b) 
Task 5

Deliverable:

Task-Level Deliverable and Metrics

$12 / 28 / 12$

Demonstration in at least five buildings of three different building system solutions that are capable of reducing annual energy use by 20 percent, drawing from integration of advanced HVAC, lighting, control, envelope and other technologies.

If changed, please insert most recent Task deliverable here:

Metrics: $\quad 12 / 28 / 12$

5.1 Matrix Update

Percent complete for each square in matrix

Stages of Development

Screening

Preliminary BIdg Assesment

Detailed BIdg Assessment

Execute Retrofit

Post-retrofit analysis

Building

Building 1

Building 2

Building 3

Building 4

Building 5

Q1

Q2

Q2

Q1

Q1 Q2

Q1 Q2

Q2

Q2

Q1

Q2

Q2

Q3

Q3

Q3

Building $\mathbf{n}$ 
Task 6

Deliverable:

Task-Level Deliverable and Metrics

$12 / 28 / 12$

Ten market-based or behaviorally oriented strategies, tools, approaches, or programs delivered to public and private sector decision makers that could yield up to $\mathbf{3 0} \%$ annual energy savings in applicable commercial buildings.

If changed, please insert task-level deliverable here:

Metrics:

$12 / 28 / 12$

6.1 Quantity of Content Track, by phase of development (conceptual, draft, review, deploy), the number of subtask strategies, tools, studies, or other content that have at least a $50 \%$ likelihood of producing an output during the course of the budget period. Each of these efforts should be measured on the likelihood for achieving up to $30 \%$ energy reduction impact when delivered.

A minimum of $Z$ strategies completed by:

$\begin{array}{lcccc} & \text { Conceptual } & \text { Draft } & \text { Review } & \text { Deploy } \\ \text { Subtask 1 } & \text { Q1 } & \text { Q2 } & \text { Q3 } & \text { Q4 } \\ \text { Subtask 2 } & \text { Q1 } & \text { Q2 } & \text { Q3 } & \text { Q4 } \\ \text { Subtask 3 } & \text { Q1 } & \text { Q2 } & \text { Q3 } & \text { Q4 } \\ \text { Subtask 4 } & \text { Q1 } & \text { Q2 } & \text { Q3 } & \text { Q4 }\end{array}$

6.2 Content Delivery Track the actual delivered outputs and how they are delivered, either in the form of papers/reports; workshops or content briefings, or through individual or small decision making group engagements.

$\begin{array}{lcccc} & \text { Planned } & \text { In-Process } & >50 \% \text { Comp } & \text { Q3 } \\ \text { Subtask 1 } & \text { Q1 } & \text { Q2 } & \text { Q4 } & \text { Q3 } \\ \text { Subtask 2 } & \text { Q1 } & \text { Q2 } & \text { Q3 } & \text { Q4 } \\ \text { Subtask 3 } & \text { Q1 } & \text { Q2 } & \text { Q2 } & \text { Q3 }\end{array}$

6.3 Market Engagement Track the interactions/frequency with targeted public or private decision makers, using the Hub's Platforms as much as practical, under planned content to reach full engagement

Subtask 1

Subtask 2

Identified

Subtask 3

Q1

Contacted

Subtask 4

Q1

Q1

Q2

Q2

Q2

Q2

Preliminary

Q3

On-Going

Q4

Q4

Q3

Q3

Q4 
Task 7

Deliverable:

$12 / 28 / 12$

Deliverable and Metrics

commercial buildings based on findings from field testing of an education and outreach program.

If changed, please insert most recent Task deliverable here:

Metrics:

01/09/13

7.1 Competency Gaps

7.1 .1

Research and evaluation of courses for success in identifying critical compentencies

Number of Hub-generated courses/curricula evaluated

7.1.2 Number of Non-Hub courses/curricula evaluated

7.2 New Standards

Development of new coursework and standards (that fill competency gaps identified???)

7.2.1

7.3 Market Engagement

7.3.1

Engagement with building eduational stakeholders

Number of national partners engaged

Number of educational delivery channels 
Task 8

Task-Level Deliverable and Metrics

Deliverable: $\quad 12 / 28 / 12$

Advanced energy retrofit investment practices demonstrated in 20 projects capable of achieving $30 \%$ annual energy savings a executed by integrated teams of large and small enterprises including minority and women owned firms.

If changed, please insert most recent Task deliverable here:

Metrics: $\quad 01 / 09 / 13$

8.1 Market Assessment Evaluation of current financing conditions pre-Hub and post-Hub

8.1.1 Number of existing financing conditions established pre-Hub

8.1.2 Number of new financing conditions established or existing conditions modified since EEB Hub

8.2 Engagement

Adequate development pipeline of investment practices to achieve $30 \%$ or more annual energy savings in at least 20 building energy retrofit

8.2.1

8.2 .2

8.2 .3

8.2 .4

Number of project identified

Number of projects completed

Measured percentage energy reduction

Number of businesses engaged in projects

8.3 Partnerships

8.3.1

8.3.2

8.3 .3

8.3 .4

8.3 .5

Extent of stakeholder engagement to develop needed retrofit investment practices

Number of businesses advised

Number of consulting hours

Number of partnering relationships

Number of businesses convening events

Number of attendees at events 
Task 9

Deliverable:
Task-Level Deliverable and Metrics

$12 / 28 / 12$

Information exchange on EEB Hub content, research and tools with $\mathbf{5 0 0}$ stakeholders along the advanced energy retrofit value chain facilitating adoption of approaches to enable 20-50 percent energy reduction in commercial buildings through advanced energy retrofit.

If changed, please insert most recent Task deliverable here:

Metrics: $\quad 01 / 09 / 13$

9.1 Impact Assessment

An impact assessment of 12 stakeholder engagements in BP3 (e.g., selected from platform events, workshops, and integrated solution showcases) to get in to 8 weeks after the event on how the event impacted thinking and actions.

9.2 Stakeholder Reach The number of independent external stakeholders engaged in platform events, workshops, integrated solutions showcases, and knowledge platformdown compared to the target of 500 . 
Deliverable:

01/09/13 All required reports are submitted on-time to the DOE. To do this, the following activities must be completed:

- Administrative guidelines and report templates are routed to task leaders at least three (3) weeks prior to submission to DOE

- Task leaders provide input for the reports no later than (NLT) the 10th of the month in which the reports are due. This permits compilation, editing and routing of draft reports for Operating Committee (OC) review

- OC review of the draft reports is complete NLT the 25 th of the month that the reports are due. This provides times for final editing to ensure submission to DOE NLT than the 30th of each month

If changed, please insert most recent Task deliverable here:

Metrics:

01/09/13

10.1 Web Reporting

Deployment of web-based reporting for all tasks

10.2 On-Time Reporting

Percent of task leaders that provide input into SharePoint for quarterly report by the $10^{\text {th }}$ in the month it is due 